Cahiers de recherches médiévales

Journal of medieval studies

2 | 1996

Regards sur le Moyen Âge

\title{
Regards sur Clovis
}

Éric Mension-Rigau

\section{OpenEdition}

Journals

Édition électronique

URL : https://journals.openedition.org/crm/2474

DOI : $10.4000 / \mathrm{crm} .2474$

ISSN : $1955-2424$

Éditeur

Honoré Champion

Édition imprimée

Date de publication : 12 décembre 1996

Pagination : 7-8

ISSN : 1272-9752

\section{Référence électronique}

Éric Mension-Rigau, "Regards sur Clovis », Cahiers de recherches médiévales [En ligne], 2 | 1996, mis en ligne le 04 février 2008, consulté le 15 décembre 2022. URL : http://journals.openedition.org/crm/2474 ; DOI : https://doi.org/10.4000/crm.2474 


\section{ARM}

\section{Regards sur Clovis}

La publication de ce deuxième numéro des Cahiers de recherches médiévales coïncide avec un événement qui a suscité, depuis quelques mois, une polémique d'une étonnante ampleur, dépassant très largement le cercle des médiévistes: le $1500^{\circ}$ anniversaire du baptême de Clovis. Une question domine le débat: quel Clovis placer au centre de la commémoration? Le chef mérovingien, vaillant guerrier et grand rassembleur? II le mérite, certes, car son rôle militaire et politique dans l'émergence de la puissance franque, au sein de la Gaule de l'Empire romain en décomposition, est incontestable: il a soumis les tribus franques à son autorité ; sa conversion a permis de rallier au nouveau pouvoir l'aristocratie galloromaine, pépinière des évêques dont l'autorité, dans les diocèses, n'était pas seulement religieuse : en trois grandes étapes (Soissons, Tolbiac, Vouillé), il a fait de son petit royaume correspondant à l'actuelle Belgique un vaste territoire s'étendant de la Thuringe aux Pyrénées.

A côté du Clovis « historique », le Clovis «mythique » a cependant sa place. Présent sans discontinuité dans l'imaginaire national depuis mille cinq cents ans, indissociable de quelques « lieux de mémoire" (Soissons et son vase, Paris et sainte Geneviève, Reims et sa cathédrale...), ce Clovis s'est élaboré dans la longue durée. Chargé d'incarner les valeurs de la chevalerie, il a été identifié à saint Louis à la fin du Xve siècle, au lendemain de la terrible épreuve de la guerre de Cent Ans au cours de laquelle commence à naître véritablement le sentiment d'appartenance à la communauté nationale. Plus tard, le siècle des Lumières, au risque de l'anachronisme le plus audacieux, a vu en lui l'inventeur de la monarchie constitutionnelle: les assemblées de guerriers francs étaient, aux yeux des philosophes, l'embryon des États généraux. Au XIX siècle, enfin, l'affrontement violent des deux France, la révolutionnaire laïque et la royaliste catholique, lui donne un nouveau souffle : il devient le point de ralliement de ceux pour lesquels la religion chrétienne est inséparable de l'essence de la France, sans pour autant être oublié par les historiens républicains comme Lavisse. On comprend qu'il intéresse, aujourd'hui encore, un public large et des historiens pourtant spécialistes d'autres époques que le Moyen Age: il me plait de l'évoquer en ouverture d'un ouvrage rassemblant des articles qui soulignent la persistance de figures, de motifs, de thèmes médiévaux sur une longue durée, jusque dans les formes de littérature les plus contemporaines.

A l'évidence, cette commémoration est pourtant délicate. Afin d'éviter le piège d'une exploitation « identitaire » de Clovis, la commémoration peut être l'occasion de réfléchir à la manière dont se construit progressivement une unité nationale (dont le baptême du chef franc est une étape, avant et avec beaucoup d'autres) intégrant des peuples d'origines diverses, leur apprenant à vivre ensemble et à devenir une nation, aux valeurs partagées.

Rappelant que la religion chrétienne, longtemps en France, a encadré toute existence individuelle et collective, cette commémoration est aussi une occasion de réfléchir à l'originalité des rapports qu'entretiennent, dans notre pays, le politique et le religieux. A cet égard, le "mythe Clovis" résume en quelque sorte les traits majeurs de "l'exception française" : précoce identité nationale, royauté sacrée rayonnante dont la signature populaire était le toucher des écrouelles, poids sans égal de la France dans la chrétienté occidentale des croisades à la fin du XIX ${ }^{e}$ siècle, indépendance traditionnelle de l'Église nationale à l'égard 


\section{Eric MENSION-RIGAU}

de la papauté du concordat de Bologne (1516) à la Révolution, glissement depuis le XIX siècle d'une "gallicanie » à une "laïcanie", de la religion d'État catholique à une laïcité d'État qui étonne partout ailleurs, notamment en pays protestants. Commémorer, c'est aussi dresser un bilan. Dans quelle mesure la France d'aujourd 'hui, drapée dans ses trois couleurs, est-elle la synthèse de deux mémoires vivantes, celle de Clovis-Jeanne d'Arc et celle des soldats de l'an II ? telle est la question à laquelle la commémoration - et le cortège de réactions qu'elle suscite - peuvent aider à répondre, tout en soulignant aussi, en définitive, l'intérêt, la proximité et l'actualité de cette période du Moyen Age pourtant la plus lointaine...

${ }^{1}$ E. Mension-Rigau est l'auteur, en collaboration avec P. Chaunu, de l'ouvrage Baptême de Clovis, baptême de la France, Paris, Balland, 1996. 